\title{
Influence of trivalent rare earth (Dy3+) ions substitution on the structural, magnetic and dielectric properties of nanosized Ni0.6Cd0.4DyxFe2-xO4 ferrites
}

Hemant Kumar Dubey

Banaras Hindu University Faculty of Science

Preeti Lahiri ( $\nabla$ plahiri16@yahoo.com )

Banaras Hindu University Faculty of Science https://orcid.org/0000-0002-6315-8740

\section{Nano Express}

Keywords: Spinel ferrite nanoparticles, XRD, Magnetization, Dielectric studies

Posted Date: September 1st, 2020

DOI: https://doi.org/10.21203/rs.3.rs-65350/v1

License: (c) (1) This work is licensed under a Creative Commons Attribution 4.0 International License. Read Full License 


\section{Abstract}

In the present work, $\mathrm{Ni}_{0.6} \mathrm{Cd}_{0.4} \mathrm{Dy}_{\mathrm{x}} \mathrm{Fe}_{2-\mathrm{x}} \mathrm{O}_{4}(\mathrm{x}=0.0,0.05,0.10,0.15$ and 0.20$)$ nanoparticles (NPs) were synthesized by using sol-gel auto combustion method. The structural characterization was performed by XRD, FTIR, SEM, TEM and EDS analyses. XRD patterns confirmed that the pure and dysprosium substituted Ni-Cd ferrites are in single phase spinel structures, while a trace of $\mathrm{DyFeO}_{3}$ appears as a minor phase for higher concentrations $(x=0.10,0.15$ and 0.20). The Debye-Scherrer's method and Williamson-Hall $(\mathrm{W}-\mathrm{H})$ method were used to evaluate the crystallite sizes and lattice strain. The average crystallite size was found to be in the range from 27 to $48 \mathrm{~nm}$. FT-IR confirms the formation of spinel structure. SEM images show that reduction of grain size with Dy ${ }^{3+}$ content. Elemental composition features of samples were examined by EDS. The average particles size estimated from TEM analysis are in good agreement with results obtained from the XRD. The results showed that saturation magnetization $\left(M_{s}\right)$ decreases and coercivity $\left(\mathrm{H}_{\mathrm{c}}\right)$ increases with increase in Dy ${ }^{3+}$ concentrations. The dielectric constant and the loss tangent decrease rapidly with increasing frequency and then reaches a constant value, characteristic of normal behavior of ferrites. The dielectric constant was found to decrease with increasing Dy content in Ni-Cd ferrites. Ferrite sample with $\mathrm{Dy}^{3+}$ concentration, $\mathrm{x}=0.05$ show high dielectric constant, low dielectric loss and hence can be utilized in high frequency electrical circuits.

\section{Introduction}

Spinel ferrite materials are of prime interest due to their variety of industrial applications. Spinel ferrites are well known magnetic materials having the general chemical formula, $A B_{2} O_{4}$, where $A$ is a divalent metal ion, $B$ is a trivalent metal ion ( $\mathrm{Fe}$ ) positioned at two different crystallographic sites, tetrahedral (A sites) and octahedral (B sites) [1]. These materials are being extensively studied due to their wide applications in biomedicine, pharmaceuticals, sensors, magnetic resonance imaging, drug delivery, microwaves, high-frequency devices, information storage, and electronic chips [2-4], especially when these materials are reduced down to the nanometric sizes. The structure and electromagnetic properties of nano-spinel ferrites can be modified by the substitution of different cations. Among various spinel ferrites, nickel ferrite, a typical inverse spinel ferrite is a soft magnetic material. It shows large permeability at high frequency, remarkable high electrical resistivity, low hysteresis loss, mechanical hardness and chemical stability [5-7] that makes it suitable for use in electronic devices. In recent years, many researchers have worked on the Cd-substituted ferrites with other metal ions such as Ni, Mg, Mn, Zn, Cd and Co which further improves the magnetic, electrical and optical properties of these ferrites. A number of works are found in literature on Cd substituted nickel ferrites. The structural and magnetic properties of nanosized $\mathrm{Ni}-\mathrm{Cd}$ ferrite synthesized by the wet chemical co-precipitation method have been reported [8]. Nikumbh [9] et al. 2002 has studied the structural, electrical and magnetic properties as well as cation distribution of cadmium-substituted nickel ferrite.

A rare-earth ion in the spinel ferrite improves densification, electrical resistivity and low eddy current losses [10]. It has been shown that substitution of Fe by rare earth (RE) ions (such as $\mathrm{La}^{3+}, \mathrm{Ho}^{3+}, \mathrm{Er}^{3+}, \mathrm{Yb}^{3+}, \mathrm{Gd}^{3+}, \mathrm{Dy}^{3+}$ ) can modify the structural, magnetic and electrical properties of ferrites due to change in the cation distribution between the $A$ and $B$ sites [11]. In general, the doped rare-earth ion enters into the B-site (Fe) by displacing the corresponding number of $\mathrm{Fe}^{3+}$ from the $\mathrm{B}$-site to the A-site $[12,13]$. Such substitution by rare earth ions with large ionic radii in spinel ferrites is expected to induce strain and to significantly modify the structural, electrical as well as magnetic properties. Further, the substitution of rare earth ions at spinel ferrite create $3 d-4 f$ coupling, which help to determine magneto-crystalline anisotropy of the material. Hence it is possible to obtain good magnetic materials, which can be used in low and hiah frequency applications [14]. The properties of ferrite nanoparticles are very sensitive to the Loading [MathJax]/jax/output/CommonHTML/fonts/TeX/fontdata.js

Page 2/24 
method of synthesis, sintering conditions, composition and microstructure [15]. Researchers have used various physico-chemical methods for synthesis of nanocrystalline ferrites, viz., citrate precursor method [16], solid-state reaction [17], co-precipitation [18-19], hydrothermal [20], sol-gel technique [21], reverse micelle technique [22], etc. Amongst these approaches, the sol-gel route of synthesis is one of the simplest, efficient, cost effective and can be easily done at low temperatures. This technique has further advantages of good stoichiometric control and the production of ultrafine particles with a narrow size distribution.

Recently Bamzai [23] et al. has studied the effect of dysprosium substitution on the structural and magnetic properties of magnesium ferrite. They found that the lattice constant increased with an increase in dysprosium concentration. It has been found that no published work is available on the structural, magnetic and dielectric properties of dysprosium substituted $\mathrm{Ni}-\mathrm{Cd}$ ferrite in the literature.

In the present investigation, an effort has been made to show the effect of substitution of $\mathrm{Dy}^{3+}$ on structural, magnetic and dielectric properties of $\mathrm{Ni}_{0.6} \mathrm{Cd}_{0.4} \mathrm{Dy}_{\mathrm{x}} \mathrm{Fe}_{2-\mathrm{x}} \mathrm{O}_{4}$ spinel ferrites based on the sol gel auto combustion method.

\section{Materials And Methods}

\section{Materials and procedures}

The nanoparticles of $\mathrm{Ni}_{0.6} \mathrm{Cd}_{0.4} \mathrm{Dy}_{\mathrm{x}} \mathrm{Fe}_{2-\mathrm{x}} \mathrm{O}_{4}(\mathrm{x}=0.0,0.05,0.10,0.15$ and 0.20$)$ were synthesized by sol-gel auto combustion technique using analytical grade iron nitrate $\left[\mathrm{Fe}\left(\mathrm{NO}_{3}\right)_{3} \cdot 9 \mathrm{H}_{2} \mathrm{O}, 99.99 \%\right.$, Aldrich], nickel nitrate [Ni $\left(\mathrm{NO}_{3}\right)_{2} \cdot 6 \mathrm{H}_{2} \mathrm{O}, 98 \%$, Aldrich], cadmium nitrate [ $\mathrm{Cd}\left(\mathrm{NO}_{3}\right)_{2} \cdot 6 \mathrm{H}_{2} \mathrm{O}, 99 \%$ Merck, India], dysprosium nitrate, citric acid $\left[\mathrm{C}_{6} \mathrm{H}_{8} \mathrm{O}_{7}, 99.5 \%\right.$, Aldrich] and ammonia [ $\left[\mathrm{NH}_{3}, 28-30 \%\right.$, Aldrich]. A transparent solution was obtained by dissolving by requisites amount of metal nitrates in a minimum amount of double distilled water. An aqueous solution of citric acid was mixed with the metal nitrates solution, the molar ratio between total metal ions and citric acid was controlled at 1:1. The 1:1 ratio was kept to maintain the stability and homogeneity of the nanoferrites. The content was stirred to obtain a homogeneous solution and then was heated to $80^{\circ} \mathrm{C}$ at a heating rate of $5{ }^{\circ} \mathrm{C} / \mathrm{min}$ using a hot plate magnetic stirrer. The ammonia solution was added drop wise to maintain the $\mathrm{p}^{\mathrm{H}}$ to 7 . The sol was formed and converted in viscous gel and it began frothing when all water molecules were evaporated from the mixture. At this stage, the gel spontaneously ignited and burnt to brown colored ashes. Finally, ash sample was crushed into powder form using pestle mortar. The dried powder was calcined at $800{ }^{\circ} \mathrm{C}$ for $4 \mathrm{~h}$ in the electrical muffle furnace using a heating rate of $10^{\circ} \mathrm{C} / \mathrm{min}$. The calcined powders obtained were then pressed into pellets $(13 \mathrm{~mm} \times 2 \mathrm{~mm})$ using polyvinyl alcohol (PVA $2 \mathrm{wt}$. \%) used as the binder by applying a pressure of 5 tons. This binder was burnt out at $450{ }^{\circ} \mathrm{C}$ for $2 \mathrm{~h}$. Schematic diagram of the preparation of the $\mathrm{Ni}_{0.6} \mathrm{Cd}_{0.4} \mathrm{Dy}_{\mathrm{x}} \mathrm{Fe}_{2-\mathrm{x}} \mathrm{O}_{4}$ is shown in Fig. 1.

\section{Characterization usig different analytical techniques}

The structural characterization of the prepared samples was contacted using X-ray powder diffractometry (Rigaku miniflex-600, Japan) employing Cu- $\mathrm{K}_{\mathrm{a}}$ radiation $(\lambda=1.5405 \AA)$ to identify the phase of annealed samples. The spinel structure of ferrite system was examined by fourier transform infrared spectra (FTIR), which was recorded on a Perkin-Elmer Spectrophotometer in the range of wave numbers $400-4000 \mathrm{~cm}^{-1}$ by mixing the powder sample with solid potassium bromide $(\mathrm{KBr})$ pressed pellets. The microstructure and elemental analysis of annealed cadmium ferrite were investigated by scanning electron microscopy (SEM, ZEISS, model EVO-18 research; Germany), equipped with an energy dispersive X-ray analyzer (EDX, Oxford instrument, USA), respectively. Transmission electron Loading [MathJax]/jax/output/CommonHTML/fonts/TeX/fontdata.js 
microscopy (TEM, Tecnai G 20 TWIN; USA) was used to determine particle size. The sample for TEM analysis was prepared by dispersing the calcined $\mathrm{Ni}_{0.6} \mathrm{Cd}_{0.4} \mathrm{Dy}_{x} \mathrm{Fe}_{2-x} \mathrm{O}_{4}$ powder in acetone by ultra-sonication. The obtained suspensions were deposited on carbon-coated copper grids. Dielectric constant was measured using a pellet on which both surfaces were polished and coated with silver paint. Magnetic measurements were conducted using a SQUID magnetometer (Quantum Design MPMS- S3). The MPMS SQUID VSM system is a highly sensitive magnetometer system that combines the sensitivity of a SQUID (Superconducting Interference Device) with the higher speed of a VSM (Vibrating Sample Magnetometer). The M-H measurements were made in fields up to \pm 15 kOe at room temperature. The dielectric properties were measured by LCR meter (PSM 1735, NumetriQ 4th Ltd. U.K.) in the frequency range $10^{2}-10^{6} \mathrm{~Hz}$. In short, an LCR meter measures the inductance $(L)$, capacitance $(C)$, and resistance $(R)$ of an electronic component.

\section{Results And Discussion}

\section{$X$-ray diffraction (XRD) analysis}

Figure 2 depicts the $X$-ray diffraction (XRD) patterns of $\mathrm{Ni}_{0.6} \mathrm{Cd}_{0.4} \mathrm{Dy}_{\mathrm{x}} \mathrm{Fe}_{2-\mathrm{x}} \mathrm{O}_{4}(\mathrm{x}=0.00,0.05,0.10,0.15$ and 0.20$)$ powder calcined at $800{ }^{\circ} \mathrm{C}$ for $4 \mathrm{~h}$. XRD pattern shows that all samples exhibit a single phase cubic spinel structure with Fd3m space group. Accordingly, XRD patterns were indexed with (220), (311), (222), (400), (422), (511), (440) and (533) respectively. The peaks are indexed by using JCPDS data card No. 86-2267. The broadening of the diffraction peaks with increasing $\mathrm{Dy}^{3+}$ concentration reflecting thereby lower crystallinity of the samples. No characteristic peaks of impurities were detected in the pattern for composition $(x=0.05)$ of $\mathrm{Dy}^{3+}$ content indicate rare earth ions have been dissolved completely into the crystal lattice of $\mathrm{Ni}_{0.6} \mathrm{Cd}_{0.4} \mathrm{Dy}_{0.05} \mathrm{Fe}_{1.95} \mathrm{O}_{4}$. However, remaining three samples $(x=0.10,0.15,0.20)$ reflected growth of secondary orthoferrite phase $\left(\mathrm{DyFeO}_{3}\right)$ with low intensity implies that the major part of $\mathrm{Dy}^{3+}$ ions are occupying the octahedral sites of the spinel lattice and only small amount of dysprosium form the $\mathrm{DyFeO}_{3}$ phase $(\mathbf{S})$. The large ionic radii of the dysprosium ions make it difficult to enter the spinel lattice and that can put a limit on the amount of rare earth doping in ferrites. It is observed that the strongest diffraction peak corresponding to (311) plane in rare earth doped samples shows a slight left shift in $2 \theta$ value relative to undoped sample indicating the lattice strain induced by the dopant ions.

The structural parameters like average crystallite size $(D)$, theoretical density $\left(\rho_{x}\right)$, bulk density $\left(\rho_{b}\right)$ and experimental lattice constant $\left(\mathrm{a}_{\text {exp }}\right)$ were calculated from XRD data using earlier reported formula $[21,24]$ and included in the Table 1. The average crystallite size of samples lies within range of $27 \mathrm{~nm}$ to $49 \mathrm{~nm}$, which confirms that the synthesized powders have a nanocrystalline nature. However it also exhibited the non-linear pattern [25]. Due to larger size of rare earth ions induces crystal imperfection and produces micro-strain, therefore utilizing WilliamsonHall equation to analyze XRD pattern is more appropriate than the Scherrer's equation [26]. Considering the size and strain effect, the Williamson-Hall equation for actual broadening $(\beta)$ can be evaluated as follows [27]:

$$
\beta=(k \lambda / D \cos \theta)+4 \tan \theta
$$

1

$(k \lambda / D \cos \theta)$ is broadening due to the size (D) and $4 \varepsilon \tan \theta$ is broadening due to strain $(\varepsilon)$. The modification of Eq. (2) yields:

$$
\beta \cos \theta=(k \lambda / D)+4 \epsilon \sin \theta
$$

Loading [MathJax]/jax/output/CommonHTML/fonts/TeX/fontdata.js 
where, $\varepsilon$ is the average micro strain. Equation (Eq.3) is an equation of a straight line with $\beta \cos \theta$ (along Y-axis) and 4 $\sin \theta$ (along $X$-axis) yields intercept as crystallite size and the slope as strain. The Williamson-Hall plots for $\mathrm{Ni}_{0.6} \mathrm{Cd}_{0.4} \mathrm{Dy}_{\mathrm{x}} \mathrm{Fe}_{2-x} \mathrm{O}_{4}$ nanoparticles are shown in Fig.3. We have noticed that the intercept values gradually increase to higher values and the slope of the plot changing from negative to the positive with $\mathrm{Dy}^{3+}$ content. The negative slope of pure and Dy $(x=0.05)$ substituted $\mathrm{Ni}-\mathrm{Cd}$ ferrites indicates the presence of compressive strain in the material whereas the positive slopes for the Dy content $(x=0.10,0.15,0.20)$ in $\mathrm{Ni}_{0.6} \mathrm{Cd}_{0.4} \mathrm{Dy}_{\mathrm{x}} \mathrm{Fe}_{2-\mathrm{x}} \mathrm{O}_{4}$ indicate the tensile strain [28]. Also, the shifting the slope values from negative to positive with higher Dy ${ }^{3+}$ content (Fig.3) indicates that expanding the crystal lattices by changing the strain from compressive to tensile.

The experimental lattice parameter $\left(\mathrm{a}_{\mathrm{exp}}\right)$ of prepared samples was calculated by following formula [29]:

$$
a=d \sqrt{h^{2}+k^{2}+l^{2}}
$$

\section{3}

The experimental lattice constant of samples increases with dysprosium content may be attributed to the exchange of larger ionic radii of $\mathrm{Dy}^{3+}$ in the arrangement of the smaller $\mathrm{Fe}^{3+}$ ions. This causes an expansion of unit cell.

Observed values (Table 1) for $\rho_{\mathrm{x}}$ and $\rho_{\mathrm{b}}$ show that as the concentration of Dy ${ }^{3+}$ increased, both theoretical and bulk density increased because it mainly depends on the molecular weight. The magnitudes of bulk densities are smaller than that of the corresponding theoretical-densities and this difference in magnitude may be due to the existence of pores in the samples, which were developed during the sample preparation or sintering process.

Porosity $(P)$ of the ferrite samples is determined by employing the relation:

$$
P \%=\left(1-\frac{\rho_{b}}{\rho_{X}}\right) \times 100
$$

\section{4}

Table 1 depicts that the porosity increases with Dy content. Utilizing the value of lattice constant (a), the distance between magnetic ions available in the tetrahedral (A-site), octahedral (B-site) i.e. hopping lengths $\left(L_{A} \& L_{B}\right)$ respectively was calculated by using the following relations:

$$
L_{A}=\frac{a \sqrt{3}}{4} \quad \text { and } \quad L_{B}=\frac{a \sqrt{2}}{4}
$$

Calculated values of hopping lengths are given in Table 1, which show that the $L_{A}$ and $L_{B}$ increased with the increase in Dy content because $L_{A}$ and $L_{B}$ are directly proportional to lattice parameter (from Eq. 5).

\section{FTIR analysis}

Fig. 4 demonstrates the FTIR spectra of the prepared $\mathrm{Ni}_{0.6} \mathrm{Cd}_{0.4} \mathrm{Dy}_{\mathrm{x}} \mathrm{Fe}_{2-\mathrm{x}} \mathrm{O}_{4}(\mathrm{x}=0.00,0.05,0.10,0.15,0.20)$ nanocrystalline samples in the wave number range $900-400 \mathrm{~cm}^{-1}$. Infrared spectroscopy is one of the important tools for assigned to vibration of ions in the crystal lattice. Generally, all spinels and ferrite shows two main broad 
represents the intrinsic vibration of tetrahedral metal-oxygen bond, while the lower absorption band $v_{2}$ in the range of $450-480 \mathrm{~cm}^{-1}$ assigned to the octahedral metal-oxygen bond [30,31]. In case of ferrites, Waldron [32] has reported that the bond distance of Fe-O at tetrahedral site $(1.89 \AA)$ is smaller than the bond distance at octahedral site $(1.99 \AA)$. Hence, the band frequency of $v_{1}$ is higher than the $v_{2}$ absorption band [33]. Table 2 includes values of IR, $v_{1}$ at $616,610,587,578,577 \mathrm{~cm}^{-1}$ and corresponding $v_{2}$ values at $473,472,466,458,458, \mathrm{~cm}^{-1}$ for the compositions $x=0.00,0.05,0.10,0.15,0.20$ respectively. The IR spectra (Fig. 4) indicate that values of $v_{1}$ and $v_{2}$ shift to lower frequency side and also a slight broadening of the absorption band is also noticed with increasing dysprosium content. This may be attributed to the substitution of smaller $\mathrm{Fe}^{3+}$ ions by larger $\mathrm{Dy}^{3+}$ ions. Therefore, the increasing site radius and absorption band shift towards the lower frequency side. Similar results have been reported for $\mathrm{Tb}^{3+}$ doped nickel ferrite nanoparticles [34].

The force constant of the tetrahedral $\left(\mathrm{K}_{\mathrm{t}}\right)$ and octahedral site $\left(\mathrm{K}_{\mathrm{o}}\right)$ have been evaluated by employing the method suggested by Waldron as given by the relation:

$$
K=4 \Pi^{2} c^{2} \mu \nu^{2}
$$

6

where, ' $\mu$ ' represents the reduced mass of the cations occupying tetrahedral and octahedral sites, $v$ is the corresponding wave number and ' $c$ ' is speed of light in free space. The calculated values of force constant for $K_{t}$ and $\mathrm{K}_{\mathrm{o}}$ are included in the Table 2.

\section{SEM Micrograph}

Surface morphology and grain size of $\mathrm{Ni}_{0.6} \mathrm{Cd}_{0.4} \mathrm{Dy}_{x} \mathrm{Fe}_{2-\mathrm{x}} \mathrm{O}_{4}(\mathrm{x}=0.00,0.05,0.10,0.15,0.20)$ NPs were determined by using scanning electron microscope. The SEM images of the samples after calcined at $800{ }^{\circ} \mathrm{C}$ were depicted in Fig. 5. The SEM micrographs of all the samples show agglomerated porous like structure which is the characteristic of sol-gel combustion method. During the sol-gel combustion synthesis, large volume of gases released, which can cause pores and voids in the samples. The linear intercept technique (LIT) was employed to measure the grain size [35]. Average grain size $(44 \mathrm{~nm}-65 \mathrm{~nm})$ was found to increase with Dy ${ }^{3+}$ contents in Ni-Cd ferrite. This fact was supported by the results of the X-ray diffraction data, where the cell parameter 'a' values increase with increasing Dy content which results in larger unit cell volume for substituted samples. Similar types of results have been reported in literature for rare earth substituted spinel ferrites [36, 37].

Qualitative and quantitative EDS analysis

Energy dispersive $\mathrm{X}$-ray spectroscopy (EDS) and elemental mapping for $\mathrm{Ni}_{0.6} \mathrm{Cd}_{0.4} \mathrm{Dy}_{\mathrm{x}} \mathrm{Fe}_{2-\mathrm{x}} \mathrm{O}_{4}(\mathrm{x}=0.00,0.05,0.10$, 0.15 and 0.20 ) are shown in Fig. 6(a)-6(b) respectively. Peaks in EDS correspond to the elements and peaks height associated to the concentration. The results confirmed the presence of the expected elements in the prepared composition such as $\mathrm{Ni}, \mathrm{Cd}, \mathrm{Fe}$, Dy and $\mathrm{O}$ also reveal an absence of any impurities during the synthesis route. Quantitative estimation of elements present in the material through its weight percentages is given in Table 3. The experimental data was provided directly by the EDS spectrum whereas theoretical data was evaluated based on the formula $\mathrm{Ni}_{0.6} \mathrm{Cd}_{0.4} \mathrm{Dy}_{x} \mathrm{Fe}_{2-x} \mathrm{O}_{4}$. In our case, it has been observed that experimental values are in close approximation with theoretically calculated values thereby suggesting the formation of pure and Dy substituted $\mathrm{Ni}_{0.6} \mathrm{Cd}_{0.4} \mathrm{Fe}_{2} \mathrm{O}_{4}$. Also, the elemental mapping of the pure and Dy substituted samples demonstrate the homogeneous distribution of nickel, iron, cadmium, dysprosium and oxygen throughout the material. 
Figure 7(a) shows the bright TEM image of the samples $\mathrm{Ni}_{0.6} \mathrm{Cd}_{0.4} \mathrm{Dy}_{x} \mathrm{Fe}_{2-x} \mathrm{O}_{4}$. The TEM results reveal that the nanoparticles are almost round in shape and are slightly agglomerated. The average particle size was evaluated using Image $\mathrm{J}$-software and obtained values lie in the range $28-49 \mathrm{~nm}$ (Table 2). This agglomeration can be credited to high magnetic interactions among the nanoparticles. Similar kinds of observations were reported by Naidu [38] et al. in the literature. The average particle sizes obtained from TEM investigation are in good agreement with the crystallite sizes got from XRD analysis. Selected area electron diffraction (SAED) analysis of all the compositions shown in Fig. 7(b) illustrates spotty circular rings patterns that confirm crystallinity.

Magnetic Studies

Figure 8 represents $\mathrm{M}-\mathrm{H}$ hysteresis loops of the nanosized $\mathrm{Ni}_{0.6} \mathrm{Cd}_{0.4} \mathrm{Dy}_{\mathrm{x}} \mathrm{Fe}_{2-\mathrm{x}} \mathrm{O}_{4}$ spinel ferrites at room temperature. It is evident from the results that the $S$ shaped loops illustrated ferromagnetic nature [39] of the Dy ${ }^{3+}$ substituted and un-substituted spinel ferrites. The magnetic parameters such as saturation magnetization $\left(M_{s}\right)$, remanence $\left(M_{r}\right)$, coercively $\left(H_{C}\right)$ and squareness ratio $\left(M_{r} / M_{S}\right)$ were calculated from the hysteresis loops for all the samples are given in Table 4.Various factors can affect the magnetic properties of spinel ferrites, including the crystallite size change, variations in magnetic moments $\left(\mu_{\mathrm{B}}\right)$, the nature and concentration of different sites, the preferred site occupancy of different ions and ionic radii of rare earth [40].

In our case, the $\mathrm{M}_{\mathrm{S}}$ and $\mathrm{M}_{\mathrm{r}}$ values decrease with increase in $\mathrm{Dy}^{3+}$ content in $\mathrm{Ni}_{0.6} \mathrm{Cd}_{0.4} \mathrm{Dy}_{\mathrm{x}} \mathrm{Fe}_{2-\mathrm{x}} \mathrm{O}_{4}$ spinel ferrite. In order to explain such behavior of the saturation magnetization, the mechanism of super-exchange interaction was taken into considerations. Generally, in spinel ferrite magnetic ions occupy at A and B sites, therefore three types of super-exchange interactions take place such as $A-A, B-B$ and $A-B$ interactions. Among these, $A-B$ interactions predominate over other two interactions. Thus, net magnetization of lattice is given by $M=M_{B}-M_{A}$. Incorporation of $\mathrm{Dy}^{3+}$ or nonmagnetic ions replaces $\mathrm{Fe}^{3+}$ ions from the octahedral sites (B), the net magnetization decreases [41]. Also, as the A-B super exchange interaction decreases, spin canting occurs at the nano-surface that leads to a decrease in the magnetic characteristics of the synthesized samples. Furthermore, the incorporation of rare earth $(\mathrm{RE})$ ions in Ni-Cd lattice creates two new interactions rather than Fe-Fe (spin coupling of 3d electrons). The first is the $\mathrm{RE}^{3+}-\mathrm{Fe}^{3+}$ interaction which is originated from the $3 \mathrm{~d}-4 \mathrm{f}$ coupling. While the other, is the $\mathrm{RE}^{3+}-\mathrm{RE}^{3+}$ interaction which, results from indirect $4 f-5 d-5 d-4 f$ electron coupling. Both interactions reduce the magnetization of the system. An unusual increase in $\mathrm{M}_{\mathrm{S}}(54.916 \mathrm{emu} / \mathrm{g})$ observed at higher concentration of $\mathrm{Dy}^{3+}(\mathrm{x}=0.20)$ which could be due to formation of secondary phase of $\mathrm{DyFeO}_{3}$ which is antiferromagnetic in nature. Also another reason for the increase in $\mathrm{M}_{\mathrm{S}}$ may be due to increase in particle size with higher concentration of dysprosium. Generally, Coercivity depends on strain, presence of nonmagnetic atom, particle size, anisotropy and defects. The observe values of $\mathrm{H}_{C}$ increases in Ni-Cd ferrite by dysprosium contents due to an increase in magneto-crystalline anisotropy which arises due to coupling of the spin of $\mathrm{Fe}^{3+}$ with that of $\mathrm{Dy}^{3+}$ [42]. The low coercive value $(<100 \mathrm{Oe})$ makes these materials suitable for high frequency applications and as core materials $[43,44]$. Furthermore, in order to understand the effect of nano-sized domain, squareness ratio $\left(M_{r} / M_{S}\right)$ has also been evaluated for all the samples and its values are given in Table 4. It is evident that the value of squareness ratio lies between 0.05 and 0.10 . The squareness ratio value of the prepared compositions with $\mathrm{Dy}^{3+}(\mathrm{x}=0.0,0.05,0.10$ and 0.15$)$ are less than 0.5 , which points to the uniaxial anisotropy in standard magnetic materials. This uniaxial anisotropy in magnetic nanoferrites occurred as a result of surface effects [45]. The magnetic moment per formula unit in Bohr magnetron was also calculated by using following relation [46]:

$$
\mu_{B}=\frac{M_{W} \times M_{S}}{5585}
$$

Loading [MathJax]/jax/output/CommonHTML/fonts/TeX/fontdata.js 
where, $\mathrm{M}_{\mathrm{w}}$ is the molecular weight of the sample. Table 4 shows that the value of the magnetic moments is decreasing linearly with increasing dysprosium substitution in these samples which is quite consistent with the behavior of saturation magnetization. The listed magnetic parameters (Table 4) indicate the fact that the soft magnetic nature of nickel-cadmium ferrite was lost by the substitution of dysprosium.

Dielectric behavior and Loss tangent

At room temperature, the real part of dielectric constant $\left(\varepsilon^{\prime}\right)$ of $\mathrm{Ni}_{0.6} \mathrm{Cd}_{0.4} \mathrm{Dy}_{x} \mathrm{Fe}_{2-x} \mathrm{O}_{4}(\mathrm{x}=0.00,0.05,0.10,0.15,0.20)$

as a function of frequency in the range of $100 \mathrm{~Hz}-5 \mathrm{MHz}$ were studied and depicted in Fig. 9(a). The value of real dielectric constant was calculated by using the formula:

$$
\epsilon^{\prime}=\frac{C_{p} d}{\epsilon_{0} A}
$$

8

where, $C_{p}$ is the capacitance of the pellet, $\varepsilon_{0}$ permittivity of free space, $d$ is thickness of the pellet and $A$ is the area of the pellet. It is observed that all samples shows dielectric dispersion with increase in frequency as shown in Fig. 9(a). Also, the decrease in dielectric constant in lower frequency region is very fast and becomes constant at high frequency region [47]. Such dielectric dispersion with frequency in prepared materials has been explained on the basis of Maxwell-Wagner model [48].

According to this model, the dielectric structure of a ferrite is composed of in-homogeneous two layers. The first layer (grains) is quite more conducting and is separated by the second thin layer of poorly conducting (grain boundaries) thereby leading to the surface charge polarizations. The poorly conducting grain boundaries have been found to be effective at lower frequencies while fairly conducting grains is effective at high frequencies. The polarization in $\mathrm{Ni}_{0.6} \mathrm{Cd}_{0.4} \mathrm{Dy}_{\mathrm{x}} \mathrm{Fe}_{2-\mathrm{x}} \mathrm{O}_{4}$ ferrite is attributed to the electrons hopping between $\mathrm{Fe}^{2+} \leftrightarrow \mathrm{Fe}^{3+}$ and holes hopping between $\mathrm{Ni}^{3+} \leftrightarrow \mathrm{Ni}^{2+}$ and hence charges carriers reaching the grain boundaries (higher resistance) pile up thereby leading to the surface charge polarizations, hence contribute to dielectric constant at low frequencies. However, the decrease in dielectric constant with increases in frequency occurs due to the inability the charge carriers can't follow the alternating applied electric field and hence decreases the polarization.

From the figure it is evident that the value of dielectric constant increased at $x=0.05$ there after the dielectric constant decreases. This increase in dielectric constant with increase in concentration of Dy ${ }^{3+}$ ions may be due to the fact that the $\mathrm{RE}^{3+}$ ion incorporation results in the distortion of Ni-Cd ferrite lattice. This leads to an increase in Fe$\mathrm{O}$ and RE-O bond lengths at octahedral $\mathrm{B}$ sites giving rise to increase in the atomic polarizability and consequent increase in dielectric constant $[49,50]$. Also, the incorporation of $\mathrm{RE}^{3+}$ ions with larger size (compared to $\mathrm{Ni} / \mathrm{Cd} / \mathrm{Fe}$ ions) into ferrite increases the resistivity and dielectric constant [51]. The decrement in dielectric constant for 'Dy' content, $x>0.5$ could be attributed to the decreasing number of $\mathrm{Fe}^{3+}$ ions at the octahedral sites. In addition to that, the formation of secondary phase $\left(\mathrm{DyFeO}_{3}\right)$ at the grain boundaries for Dysprosium content $\mathrm{x}=0.10,0.15$ and 0.20 reduces the availability of $\mathrm{Fe}^{2+} \leftrightarrow \mathrm{Fe}^{3+}$ ion pairs at the octahedral sites. Therefore, the hopping of electrons between $\mathrm{Fe}^{2+} \leftrightarrow \mathrm{Fe}^{3+}$ also decreases and reduces dielectric constant.

The variation of dielectric loss tangent with frequency was shown in Fig. 9(b), which shows similar decreasing trend as that of dielectric constant. It is observed from Fig. 9(b) that dielectric loss tangent decreases with increase in concentration of RE ion $\left(\mathrm{Dy}^{3+}\right)$. The losses are found to be low at higher frequencies due to inhibition of the domain wall motion [52]. Ferrite material with low dielectric loss is desirable for high frequency data reading/writing in

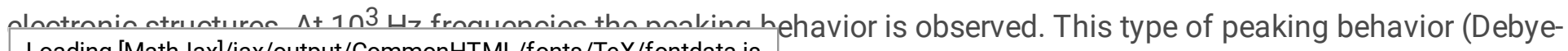
Loading [MathJax]/jax/output/CommonHTML/fonts/TeX/fontdata.js 
type relaxation) is found when the jumping frequency of the $\mathrm{Fe}^{2+} \leftrightarrow \mathrm{Fe}^{3+}$ (localized charge) ions is exactly equal to the frequency of the applied field [53]:

$\omega \tau=1(9)$

where, $\tau$ is the relaxation time of hopping process and $\omega$ is the angular frequency of the field.

\section{Conclusions}

The $\mathrm{Ni}_{0.6} \mathrm{Cd}_{0.4} \mathrm{Dy}_{\mathrm{x}} \mathrm{Fe}_{2-\mathrm{x}} \mathrm{O}_{4}(\mathrm{x}=0.0,0.05,0.10,0.15$ and 0.20$)$ ferrite calcined at $800{ }^{\circ} \mathrm{C}$ for $4 \mathrm{~h}$ were synthesized successfully by sol-gel technique. The XRD pattern revealed the formation of pure phase spinel ferrite with composition $x=0.00$ and 0.05 , while $\mathrm{DyFeO}_{3}$ phase appeared with $\mathrm{Dy}^{3+}$ composition $\mathrm{x}=0.10,0.15,0.20$. The effect of dysprosium ion $\left(\mathrm{Dy}^{3+}\right)$ on the structural, magnetic and dielectric properties of Ni-Cd ferrite was investigated. The values of crystallite size, theoretical density, bulk density and lattice parameter varied with increase in Dy ${ }^{3+}$ ions concentration. FTIR spectroscopy analysis confirms the presence of tetrahedral and octahedral sites in prepared samples. The particle size calculated from the TEM image was found to be in close agreement with the DebyeScherrer's formula. Elemental mapping and EDS results show that the particles are homogeneous without any impurity pickup. Magnetization measurement demonstrates that the saturation magnetization value decreased and coercivity has increased with increase the $\mathrm{Dy}^{3+}$ content in Ni-Cd ferrites. A normal dispersion in dielectric parameters $\left(\varepsilon^{\prime}\right.$ and $\left.\tan \delta\right)$ with frequency was observed for all samples and this has been explained on the basis of space charge polarization mechanism as discussed in Maxwell-Wagner model. In the present investigation, materials with low values of dielectric loss tangent (tan $\delta$ ) at higher frequencies would be suitable for application in high frequency micro wave devices.

\section{Declarations}

\section{Acknowledgements}

We wish to thank and acknowledge the University Grants Commission (UGC), New Delhi for providing research fellowship, RET (No.Chem.15-16/611) for empowering this work. Authors are thankful to Professor K. D. Mandal, Indian Institute of Technology (Banaras Hindu University), Varanasi, India for dielectric studies.

\section{References}

[1] D.M. Jnaneshwara, D.N. Avadhani, B.D.Prasad, H. Nagabhushana, Nagabhushana, B.M. S.C. Sharma, S.C. Prashantha, C. Shivakumara (2014) Role of $\mathrm{Cu}^{2+}$ ions substitution in

magnetic and conductivity behaviour of nano $\mathrm{CoFe}_{2} \mathrm{O}_{4}$. Spectrochimica Acta Part A: Mole. Bimole. Spectroscopy $132: 256-262$

[2] Q. Chen, ZJ Zhang (1998) Size-dependent super paramagnetic properties of spinel ferrite Nanocrystallites. Appl. Phys. Lett. 73:3156-3158

[3] L. Zhao, H. Yang, L.Yu, Y. Cui, X. Zhao, S. Feng (2007) Magnetic properties of resubstituted $\mathrm{Ni}-\mathrm{Mn}$ ferrite nanocrystallites. J. Mater. Sci. 42:686-691

[4] E.R. Kumar, A.S. Kamzin, K. Janani (2016) Effect of annealing on particle size, Loading [MathJax]/jax/output/CommonHTML/fonts/TeX/fontdata.js 
microstructure and gas sensing properties of $\mathrm{Mn}$ substituted $\mathrm{CoFe}_{2} \mathrm{O}_{4}$ nanoparticles, J. Magn.

Magn. Mater. 417:122-129

[5] A. Ahlawat, V.G. Sathe, V.R. Reddy, A. Gupta (2011) Raman study of

$\mathrm{NiFe}_{2} \mathrm{O}_{4}$ nanoparticles, bulk and films: effect of laser power. J. Magn. Magn. Mater.

323:2049-2054

[6] S. Singhal, K. Chandra (2007) Cation distribution and magnetic properties in chromiumsubstituted nickel ferrites prepared using aerosol route. J. Solid State. Chem.180:296-300

[7] S.A.S. Ebrahimi, J. Azadmanjiri (2007) Evaluation of $\mathrm{NiFe}_{2} \mathrm{O}_{4}$ ferrite nanocrystalline powder synthesized by a sol-gel auto-combustion method. J. Non-Cryst. Solids. 353:802-804

[8] S.P. Jadhav, B.G.Toksha, K.M. Jadhav, N.D. Shinde (2010) Effect of cadmium substitution on structural and magnetic properties of nano sized nickel ferrite. Chinese J. Chem. Phys. $23: 459$

[9] A.K. Nikumbh, A.V. Nagawade, G.S. Gugale, M.G. Chaskar, P.P. Bakare (2002) The formation structural electrical magnetic and Mossbauer properties of ferrite spinels. $\mathrm{Cd}_{1-x} \mathrm{Ni}_{x} \mathrm{Fe}_{2} \mathrm{O}_{4}$. J. Mater. Sci. 37:637

[10] N. Rezlescu, E. Rezlescu, D.P. Popa, L. Rezlescu (1998) Effects of rare-earth oxides on physical properties of Li-Zn ferrite. J. Alloys Comp. 657:275

[11] B. Ji, C. Tian, Q.Z. Zhang, D.D. Ji, J. Yang J.S., Xie, J. Si (2016) Magnetic properties of samarium and gadolinium co-doping Mn-Zn ferrites obtained by sol-gel auto combustion method. J. Rare Earths. 34:1017-1023

[12] V. Chaudhari, S.E. Shirsath, M.L. Mane, R.H. Kadam, S.B. Shelke, D.R. Mane (2013) Crystallographic, magnetic and electrical properties of $\mathrm{Ni}_{0.5} \mathrm{Cu}_{0.25} \mathrm{Zn}_{0.25} \mathrm{La}_{x} \mathrm{Fe}_{2-x} \mathrm{O}_{4}$ nanoparticles fabricated by sol-gel method. J. Alloys Compd. 549:213

[13] C.A. Stergiou, G. Litsardakis (2011) Electromagnetic properties of Ni and La doped strontium hexaferrites in the microwave region. J. Alloys Compd. 509:6609

[14] E. Rezlescu, N. Rezlescu, F. Tudorache, P.D. Popa (2004) Effects of replacing Fe by La or 
Gain $\mathrm{Mg}_{0.5} \mathrm{Cu}_{0.5} \mathrm{Fe}_{2} \mathrm{O}_{4}$ : humidity sensitivity. J. Magn. Magn. Mater. 272:1821

[15] K.M. Batoo, S. Kumar, C.G. Lee, Alimuddin (2009) Finite size effect and influence of temperature on electrical properties of nanocrystalline Ni-Cd ferrites. Current Appl. Phys. 9:1072-1078

[16] B.M. Mouallem, S. Bertrand, O. Pena (2005) Synthesis and characterization of $\mathrm{Zn}_{1-x} \mathrm{Ni}_{x} \mathrm{Fe}_{2} \mathrm{O}_{4}$ spinels prepared by a citrate precursor. J. Solid State Chem. 178:1080

[17] Z. Zhang, Y. Liu, G. Yao, G. Zu, Y. Hao (2012) Synthesis and Characterization of $\mathrm{NiFe}_{2} \mathrm{O}_{4}$ Nanoparticles via Solid-State Reaction. Int. J. Appl. Ceram. Technol. 10:142-149

[18] G. Vaidyanathan, S. Sendhilnathan (2008) Characterization of $\mathrm{Co}_{1-x} \mathrm{Zn}_{x} \mathrm{Fe}_{2} \mathrm{O}_{4}$ nanoparticles synthesized by co-precipitation method. Physica B: Condens. Matter. 403:2157

[19] C. Verma, H.D. Dubey, N. Farhana, P. Lahiri (2020) Structural and optical properties of nanosized Co substituted Ni ferrites by coprecipitation method, Phase Transition. 93:207

[20] Z. Wang, Y. Xie, P. Wang, Y. Ma, S. Jin, X. Liu (2011) Microwave anneal effect on magnetic properties of $\mathrm{Ni}_{0.6} \mathrm{Zn}_{0.4} \mathrm{Fe}_{2} \mathrm{O}_{4}$ nano-particles prepared by conventional hydrothermal method. J. Magn. Magn. Mater. 323:3121

[21] H.K. Dubey, P. Lahiri (2020) Synthesis, structural, dielectric and magnetic properties of $\mathrm{Cd}^{2+}$ based Mn nanosized ferrites. Mater. Technol. Adv. Perform. Mater. 5:1-14

[22] X. Gao, Y. Du, X. Liu, P. Xu, X. Han (2011) Synthesis and characterization of Co-Sn substituted barium ferrite particles by a reverse microemulsion technique. Mater. Res. Bull. $46: 643$

[23] K.K. Bamzai, G. Kour, B. Kaur, S.D. Kulkarni (2013) Effect of cation distribution on structural and magnetic properties of Dy substituted magnesium ferrite. J. Magn. Magn. Mater. 327:159

[24] D.R. Cornejo, A. Medina Boudri, J. Matutes Aquino (2002) Time-dependent magnetization in co-precipitated cobalt ferrite. Phys. B. 320:270

[25] J. Jiang, L.C. Li, F. Xu (2007) Structural analysis and magnetic properties of Gd-doped 
Li-Ni ferrites prepared using rheological phase reaction method. J. Rare Earths. 25:79

[26] V.D. Mote, Y. Purushotham, B.N. Dole (2012) Williamson-Hall analysis in estimation of lattice strain in nanometer-sized ZnO particles. J. Theoretical Appl. Phys. 6:8

[27] A.K. Zak, W.H.A. Majid, M.E. Abrishami, R. Yousefi (2011) X-ray analysis of ZnO nanoparticles by Williamson-Hall and size-strain plot methods. Solid State Sci. 13:251

[28] A. Ahlawat, V.G. Sathe, V.R. Reddy, A. Gupta (2011) Mossbauer, Raman and X-ray diffraction studies of superparamagnetic $\mathrm{NiFe}_{2} \mathrm{O}_{4}$ nanoparticles prepared by sol-gel autocombustion method. J. Magn. Magn. Mater. 323:2049

[29] H.K. Dubey, P. Lahiri (2020) Synthesis of nanosized cadmium ferrite and assaying its magnetic and dielectric properties by analytical and physical techniques. Int. J. Mater. Res. $111: 14$

[30] S. Masoudpanah, S.S. Ebrahimi, M. Derakhshani, S. Mirkazemi (2014) Structure and magnetic properties of La substituted $\mathrm{ZnFe}_{2} \mathrm{O}_{4}$ nanoparticles synthesized by sol-gel autocombustion method. J. Magn. Magn. Mater. 370122

[31] V. Chaudhari, S.E. Shirsath, M.L. Mane, R.H. Kadam, S.B. Shelke, D.R. Mane (2013) Crystallographic, magnetic and electrical properties of $\mathrm{Ni}_{0.5} \mathrm{Cu}_{0.25} \mathrm{Zn}_{0.25} \mathrm{La}_{x} \mathrm{Fe}_{2-x} \mathrm{O}_{4}$ nanoparticles fabricated by sol-gel method. J. Alloys Compd. 549:213

[32] R.D. Waldron (1955) Infrared spectra of ferrites. Phys. Res. 99:8

[33] A.B. Gadkari, T.J. Shinde, P.N. Vasambekar (2011) Synthesis, characterization and magnetic properties of $\mathrm{La}^{3+}$ added $\mathrm{Mg}-\mathrm{Cd}$ ferrites prepared by oxalate co-precipitation method. J. Alloys Compd. 509:966

[34] B.P. Jacob, S. Thankachan, S. Xavier, E.M. Mohammed (2013) Effect of $\mathrm{Tb}^{3+}$ substitution on structural, electrical and magnetic properties of sol-gel synthesized nanocrystalline nickel ferrite. J. Alloys Compnds. 578:314

[35] K.R. Rahman, F.U.Z. Chowdhury, M.N.I. Khan (2017) Structural, Morphological and Magnetic Properties of $\mathrm{Al}^{3+}$ Substituted $\mathrm{Ni}_{0.25} \mathrm{Cu}_{0.20} \mathrm{Zn}_{0.55} \mathrm{Al}_{x} \mathrm{Fe}_{2-x} \mathrm{O}_{4}$ Ferrites Synthesized 
by Solid State Reaction Route. Res. Phys. 7:354

[36] M.Z. Said (1998) Effect of gadolinium substitutions on the structure and electrical conductivity of Ni-ferrite. Mater. Lett. 34:305

[37] M. Ishaque, M.U. Islam, M.A. Khan, I.Z. Rahman, A. Genson, S. Hampshire (2010) Structural, electrical and dielectric properties of yttrium substituted nickel ferrites. Physica

1. $405: 1532$

[38] K.C.B. Naidu, W. Madhuri (2017) Hydrothermal Synthesis of $\mathrm{NiFe}_{2} \mathrm{O}_{4}$ nano-particles:

Structural, Morphological, Optical, Electrical and Magnetic Properties. Bull. Mater. Sci. $40: 417$

[39] N.U. Ain, W. Shaheen, B. Bashir, N.M. Abdelsalam, M.F. Warsi, M.A. Khan, M. Shahid (2016) Electrical, magnetic and photoelectrochemical activity of $\mathrm{rGO} / \mathrm{MgFe}_{2} \mathrm{O}_{4}$ nanocomposites under visible light irradiation. Cer. Int. 42:12401

[40] F.X. Chen, J.T. Jia, Z.G. Xu, B. Zhou, C.S. Liao, C.H. Yan, L.Y. Chen, H.B. Zhao (1999) Microstructure, magnetic, and magneto-optical properties of chemical synthesized Co-RE $(\mathrm{RE}=\mathrm{Ho}, \mathrm{Er}, \mathrm{Tm}, \mathrm{Yb}, \mathrm{Lu})$ ferrite nanocrystalline films, J. Appl. Phys. 86:2727

[41] J. Peng, M. Hojamberdiev, Y. Xu, B. Cao, J. Wang, H. Wu (2011) Hydrothermal synthesis and magnetic properties of gadolinium-doped $\mathrm{CoFe}_{2} \mathrm{O}_{4}$ nanoparticles. J. Magn. Mang. Mater. 323:133

[42] R. Jain, V. Luthra and S. Gokhale (2016) Dysprosium doping induced shape and magnetic anisotropy of $\mathrm{Fe}_{3-\mathrm{x}} \mathrm{Dy}_{\mathrm{x}} \mathrm{O}_{4}(\mathrm{x}=0.01-0.1)$ nanoparticles, J. Magn. Magn. Mater. 414:111

[43] J. Azadmanjiri, S.A. Seyyed Ebrahimi (2004) Influence of stoichiometry and calcinations condition on the microstructure and phase constitution of $\mathrm{NiFe}_{2} \mathrm{O}_{4}$ powders prepared by solgel autocombustion method. Phys. Stat. Sol. 12:3414

[44] B. Baruwati, R.K. Rana, S.V. Manorama (2007) Further insights in the conductivity behavior of nanocrystalline $\mathrm{NiFe}_{2} \mathrm{O}_{4}$. J. Appl. Phys. 101:014302

[45] I. Bashar, M. Ihab, B.A. Obaidat, Y.H. Albiss (2013) Magnetic Nanoparticles: Surface 
[46] P.P. Hankare, S.D. Jadhav, U.B. Sankpa, K.J. Waghmare, B.K. Chougule (2009) Synthesis, characterization and effect of sintering temperature on magnetic properties of MgNi ferrite prepared by co-precipitation method. J. Alloys Compnds. 475:926

[47] J. Wu, J. Wang (2009) Multiferroic behavior and impedance spectroscopy of bilayered $\mathrm{BiFeO}_{3} / \mathrm{CoFe}_{2} \mathrm{O}_{4}$ thin films. J. Appl. Phys. 105:124107

[48] M. Raghasudha, D. Ravinder, P. Veerasomaiah (2013) Influence of $\mathrm{Cr}^{3+}$ Ion on the Dielectric Properties of Nano Crystalline Mg-Ferrites Synthesized by Citrate-Gel Method. Mater. Sci. App. 4:432

[49] G. Dascalu, T. Popescu, M. Feder, O.F. Caltun (2013) Structural, electric and magnetic properties of $\mathrm{CoFe}_{1.8} \mathrm{RE}_{0.2} \mathrm{O}_{4}(\mathrm{RE}=\mathrm{Dy}, \mathrm{Gd}$, La) bulk materials. J. Magn. Magn. Mater. 33:69

[50] K.K. Bharathi, C.V. Ramana (2011) Improved electrical and dielectric properties of Ladoped Co Ferrite. J. Mater. Res. 26:584

[51] C.V. Ramana, Y.D. Kolekar, K.K. Bharathi, B. Sinha, K. Ghosh (2013) Correlation between structural, magnetic, and dielectric properties of manganese substituted cobalt ferrites. J. Appl. Phys. 114:183907

[52] R.C. Kambale, P.A. Shaikh, C.H. Bhosale, K.Y. Rajpure, Y.D. Kolekar (2009) The effect of Mn substitution on the magnetic and dielectric properties of cobalt ferrite synthesized by an autocombustion route, Smart Mater. Struct. 18:115028

[53] N. Rezlescu, E. Rezlescu (1974) Dielectric Properties of Copper Containing Ferrites. Phys. Stat. Sol A. 23575

\section{Tables}

\section{Table 1}

Structural parameters obtained from XRD such as lattice parameter $\left(\mathrm{a}_{\mathrm{exp}}\right)$, average crystallite size (D), theoretical-ray density $\left(\rho_{\mathrm{x}}\right)$, bulk density $\left(\rho_{\mathrm{b}}\right)$, porosity $(\mathrm{P} \%)$ and hopping lengths $\left(\mathrm{L}_{\mathrm{A}} \& \mathrm{~L}_{\mathrm{B}}\right)$ of the synthesized $\mathrm{Ni}_{0.6} \mathrm{Cd}_{0.4} \mathrm{Dy}_{\mathrm{x}} \mathrm{Fe}_{2-\mathrm{x}} \mathrm{O}_{4}$ ferrite.

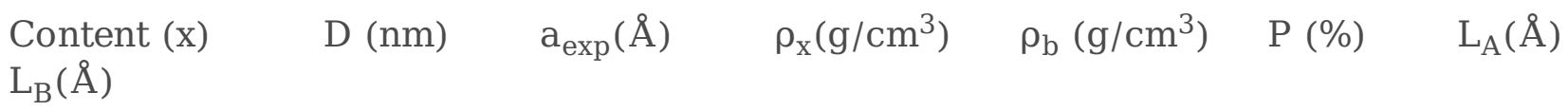




$\begin{array}{rrrrrrrr}\mathrm{X}=0.00 & 33.525 & 8.5370 & 5.6904 & 4.799 & 15.450 & 3.6966 & 3.0182 \\ \mathrm{x}=0.05 & 44.850 & 8.5376 & 5.8054 & 4.938 & 14.920 & 3.6968 & 3.0184 \\ \mathrm{X}=0.10 & 38.187 & 8.5440 & 5.9030 & 4.801 & 18.640 & 3.6995 & 3.0207 \\ \mathrm{X}=0.15 & 27.447 & 8.5446 & 6.0169 & 4.821 & 19.871 & 3.6994 & 3.0209 \\ \mathrm{x}=0.20 & 47.982 & 8.5781 & 5.6487 & 4.971 & 11.983 & 3.7144 & 3.0328\end{array}$

\section{Table 2}

Absorption band frequency, force constant and particle size (TEM analysis) of $\mathrm{Ni}_{0.6} \mathrm{Cd}_{0.4} \mathrm{Dy}_{\mathrm{x}} \mathrm{Fe}_{2-}$ ${ }_{\mathrm{x}} \mathrm{O}_{4}$ ferrites.

$\begin{array}{llllll}\begin{array}{l}\text { Dysposium } \\ \text { (TEM) }\end{array} & \nu_{1} & \nu_{2} & K_{\mathrm{t}} & \mathrm{K}_{\mathrm{o}} & \text { Particles size }\end{array}$

Content $(\mathrm{x}) \quad\left(\mathrm{cm}^{-1}\right) \quad\left(\mathrm{cm}^{-1}\right) \quad\left(10^{2} \mathrm{~N} / \mathrm{m}\right) \quad\left(10^{2} \mathrm{~N} / \mathrm{m}\right) \quad(\mathrm{nm})$

$\begin{array}{rrrrrr}\mathrm{x}=0.00 & 616 & 473 & 2.7812 & 1.6398 & 33.50 \\ \mathrm{x}=0.05 & 610 & 472 & 2.7273 & 1.6329 & 45.77 \\ \mathrm{x}=0.10 & 587 & 466 & 2.5255 & 1.5916 & 38.51 \\ \mathrm{x}=0.15 & 578 & 458 & 2.4487 & 1.5374 & 28.60 \\ \mathrm{x}=0.20 & 577 & 458 & 2.4402 & 1.5374 & 49.28\end{array}$


Table 3

Quantitative estimation of elements present in the material through its weight percentages

\begin{tabular}{|c|c|c|c|c|c|c|c|c|c|c|}
\hline Composition & & $\begin{array}{c}\text { Theoretical } \\
\text { (wt\%) }\end{array}$ & & & & & $\begin{array}{l}\text { Observed } \\
(\mathrm{wt} \%)\end{array}$ & & & \\
\hline Element & $\mathrm{Ni}(\mathrm{K})$ & $\mathrm{Fe}(\mathrm{K})$ & $\mathrm{Cd}(\mathrm{L})$ & Dy(L) & $\mathrm{O}(\mathrm{K})$ & $\mathrm{Ni}(\mathrm{K})$ & $\mathrm{Fe}(\mathrm{K})$ & $\mathrm{Cd}(\mathrm{L})$ & Dy(L) & $\mathrm{O}(\mathrm{K})$ \\
\hline$x=0.00$ & 11.11 & 43.15 & 21.27 & ---- & 24.46 & 9.08 & 42.89 & 23.29 & --- & 24.00 \\
\hline$x=0.05$ & 8.61 & 41.75 & 23.46 & 01.40 & 24.77 & 8.63 & 41.75 & 24.80 & 2.98 & 23.53 \\
\hline$x=0.10$ & 8.77 & 41.85 & 21.94 & 4.72 & 22.72 & 8.46 & 38.26 & 24.32 & 5.86 & 23.08 \\
\hline $\mathrm{x}=0.15$ & 8.62 & 36.55 & 23.86 & 8.62 & 22.64 & 8.74 & 38.74 & 23.01 & 5.44 & 24.07 \\
\hline$x=0.20$ & 8.15 & 34.91 & 23.42 & 11.28 & 22.22 & 9.61 & 34.34 & 22.27 & 8.21 & 25.57 \\
\hline
\end{tabular}

Table 4

Magnetic parameters obtained from $\mathrm{M}-\mathrm{H}$ loop analysis of the synthesized $\mathrm{Ni}_{0.6} \mathrm{Cd}_{0.4} \mathrm{Dy}_{\mathrm{X}} \mathrm{Fe}_{2-}$ ${ }_{\mathrm{x}} \mathrm{O}_{4}$ ferrite samples.

Content $(\mathrm{x}) \quad(\mathrm{emu} / \mathrm{g}) \quad(\mathrm{emu} / \mathrm{g}) \quad\left(\mathrm{O}_{\mathrm{e}}\right)$

$\begin{array}{rrrrrr}\mathrm{x}=0.00 & 37.612 & 2.190 & 40.779 & 0.05823 & 1.895 \\ \mathrm{x}=0.05 & 37.503 & 3.253 & 57.126 & 0.0867 & 1.726 \\ \mathrm{x}=0.10 & 34.090 & 2.476 & 49.325 & 0.0726 & 1.693 \\ \mathrm{x}=0.15 & 33.090 & 2.649 & 56.207 & 0.0800 & 1.693 \\ \mathrm{x}=0.20 & 54.916 & 6.032 & 72.393 & 0.1098 & 2.831\end{array}$

Figures 


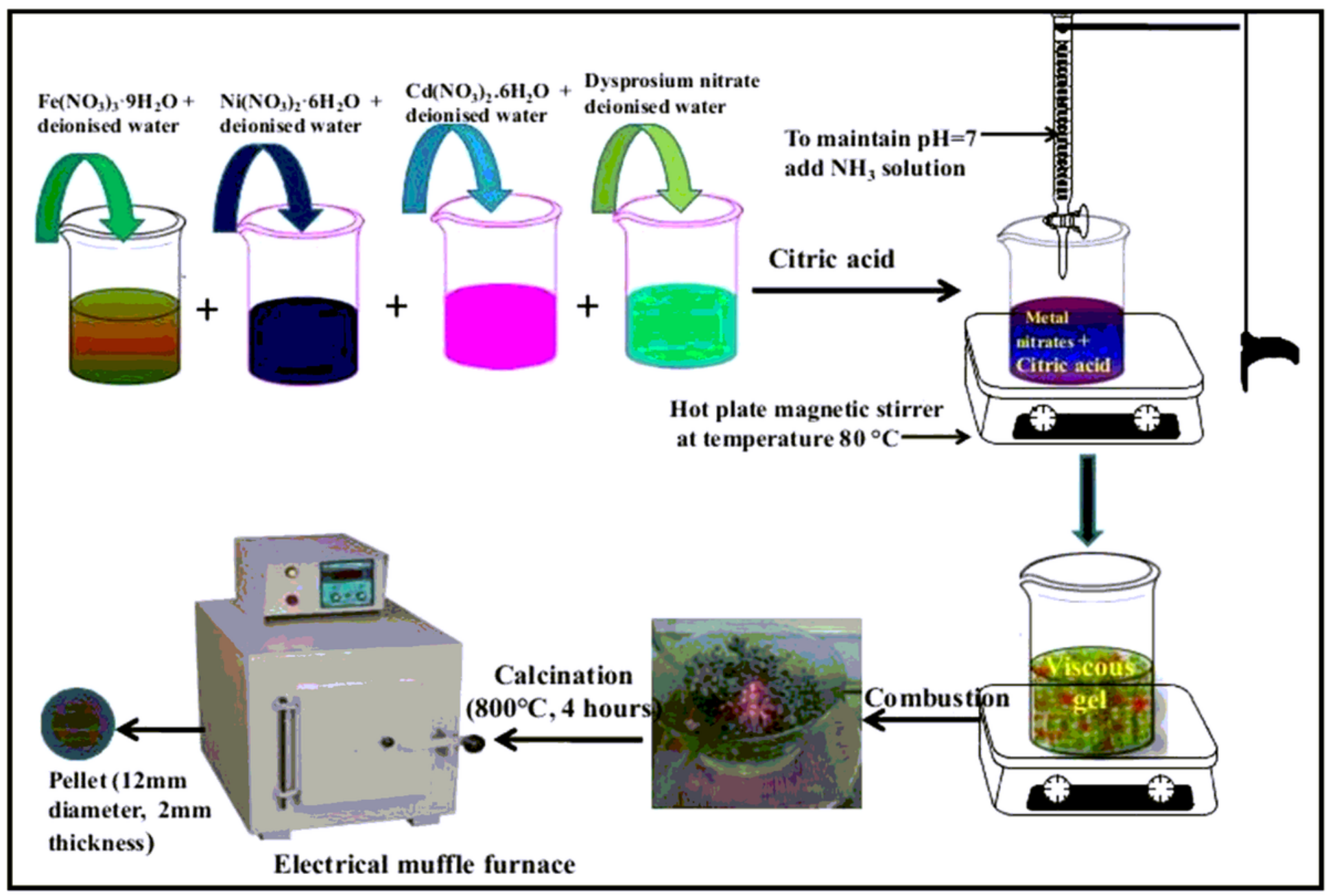

Figure 1

Schematic diagram for experimental set up of Ni0.6Cd0.4DyxFe2-xO4 ( $x=0.0,0.05,0.10,0.15$ and 0.20$)$ nanoparticles calcined at $800{ }^{\circ} \mathrm{C}$. 


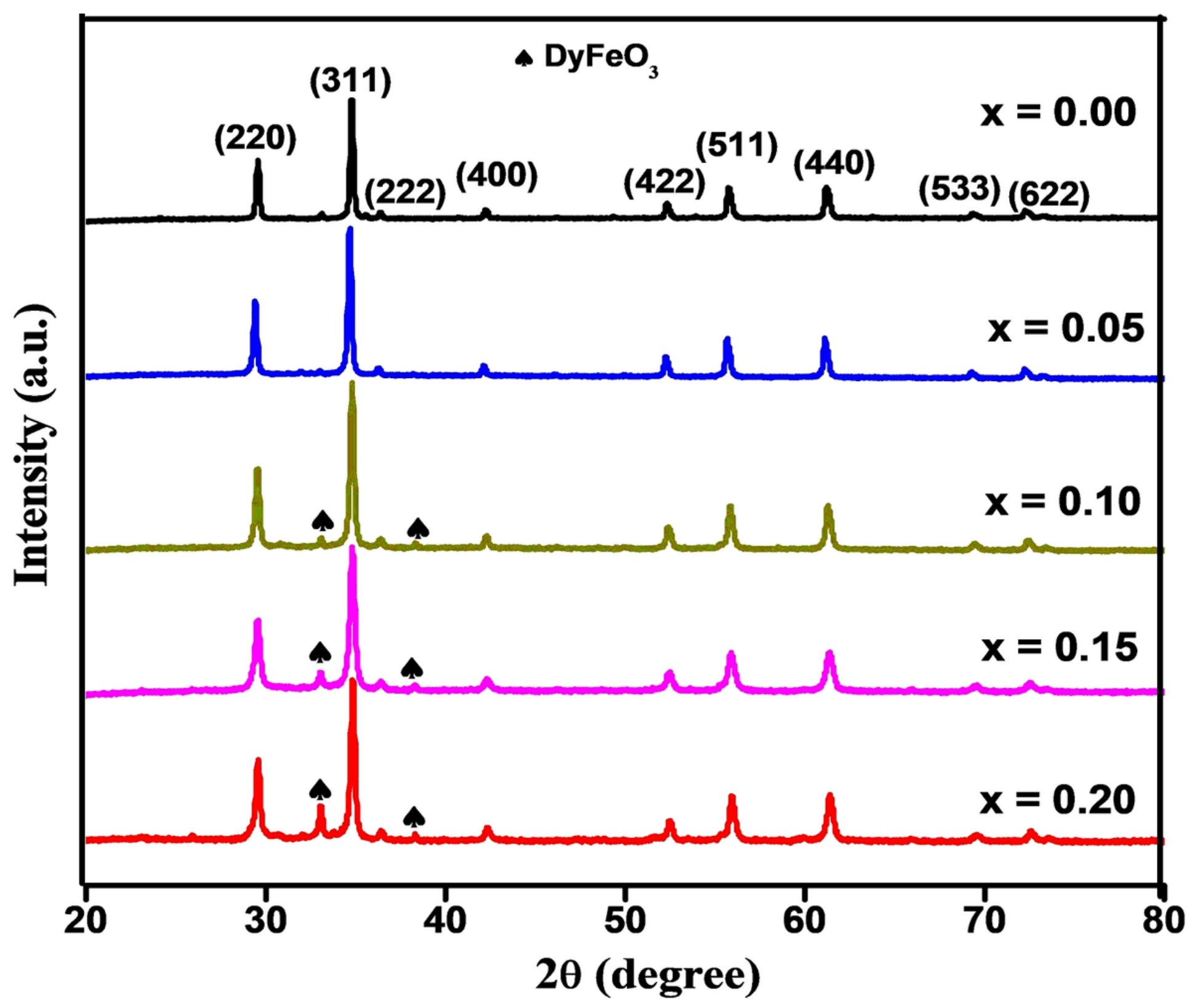

Figure 2

$\mathrm{X}$ - ray diffraction patterns of Ni0.6Cd0.4DyxFe2-xO4 ferrite calcined at $800{ }^{\circ} \mathrm{C}$ for $4 \mathrm{~h}$ are illustrated. The abscissa denotes $(\theta)$ and the ordinate denotes the frequency (arbitrary units or a.u.). 

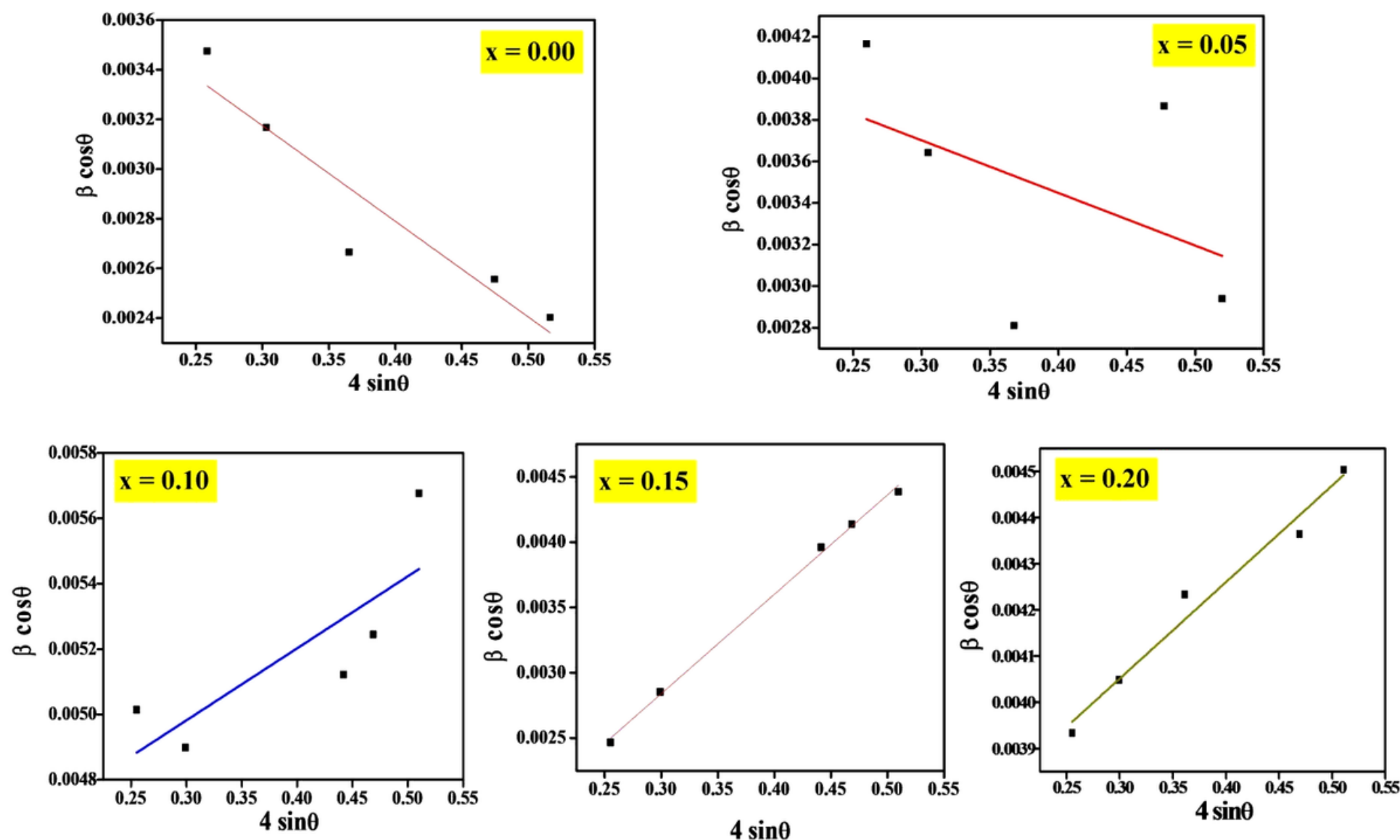

Figure 3

The $\mathrm{W}-\mathrm{H}$ Plot of Ni0.6Cd0.4DyxFe2-xO4 nanoparticles. Fit to the data, the strain is extracted from the slope and the crystalline size is extracted from the $y$-intercept of the fit. 


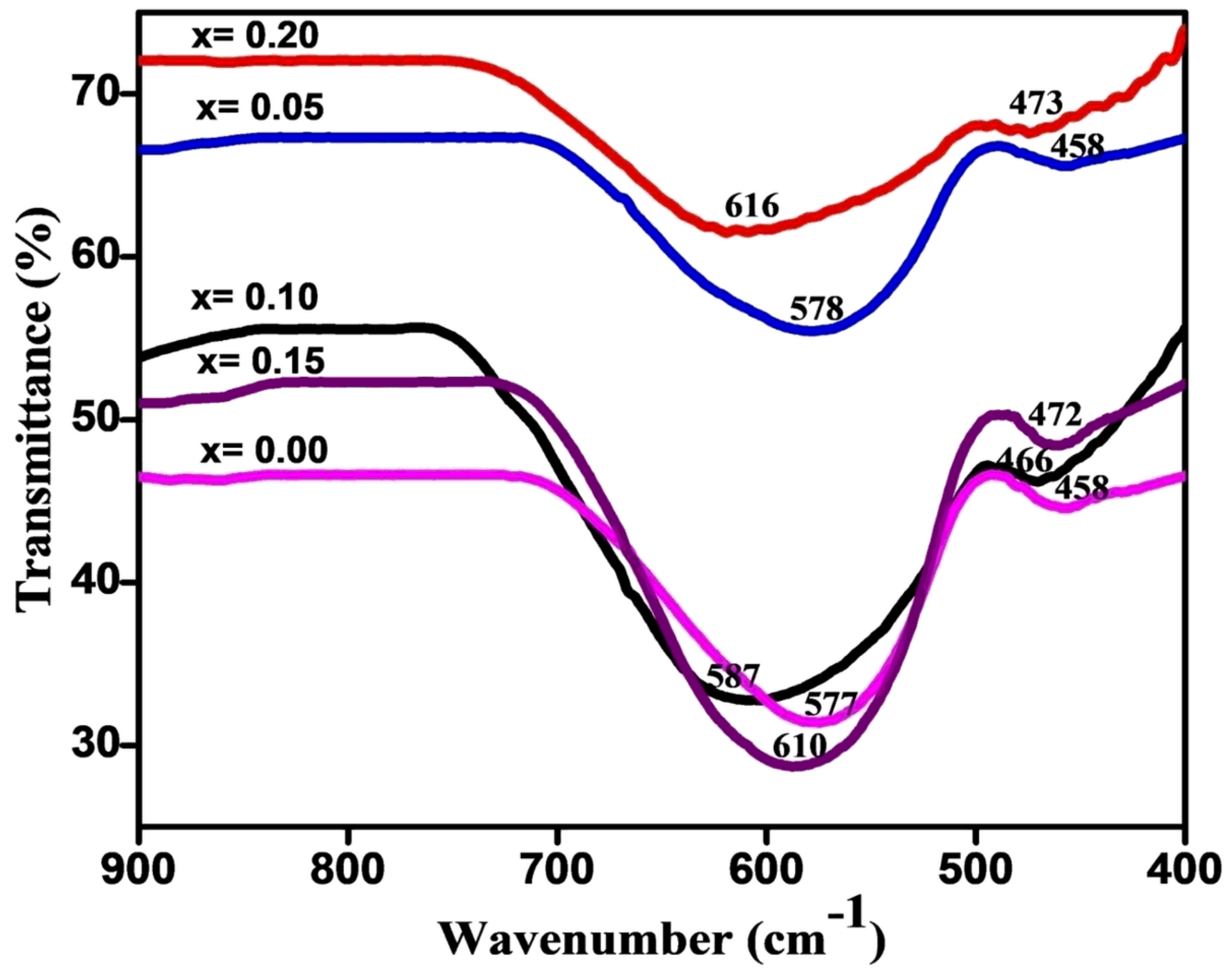

Figure 4

FT-IR spectra of Ni0.6Cd0.4DyxFe2-xO4 powders at room temperature. The presence of major absorption bands around 400 and $600 \mathrm{~cm}-1$ confirmed location the cations in tetrahedral and octahedral sites, respectively 

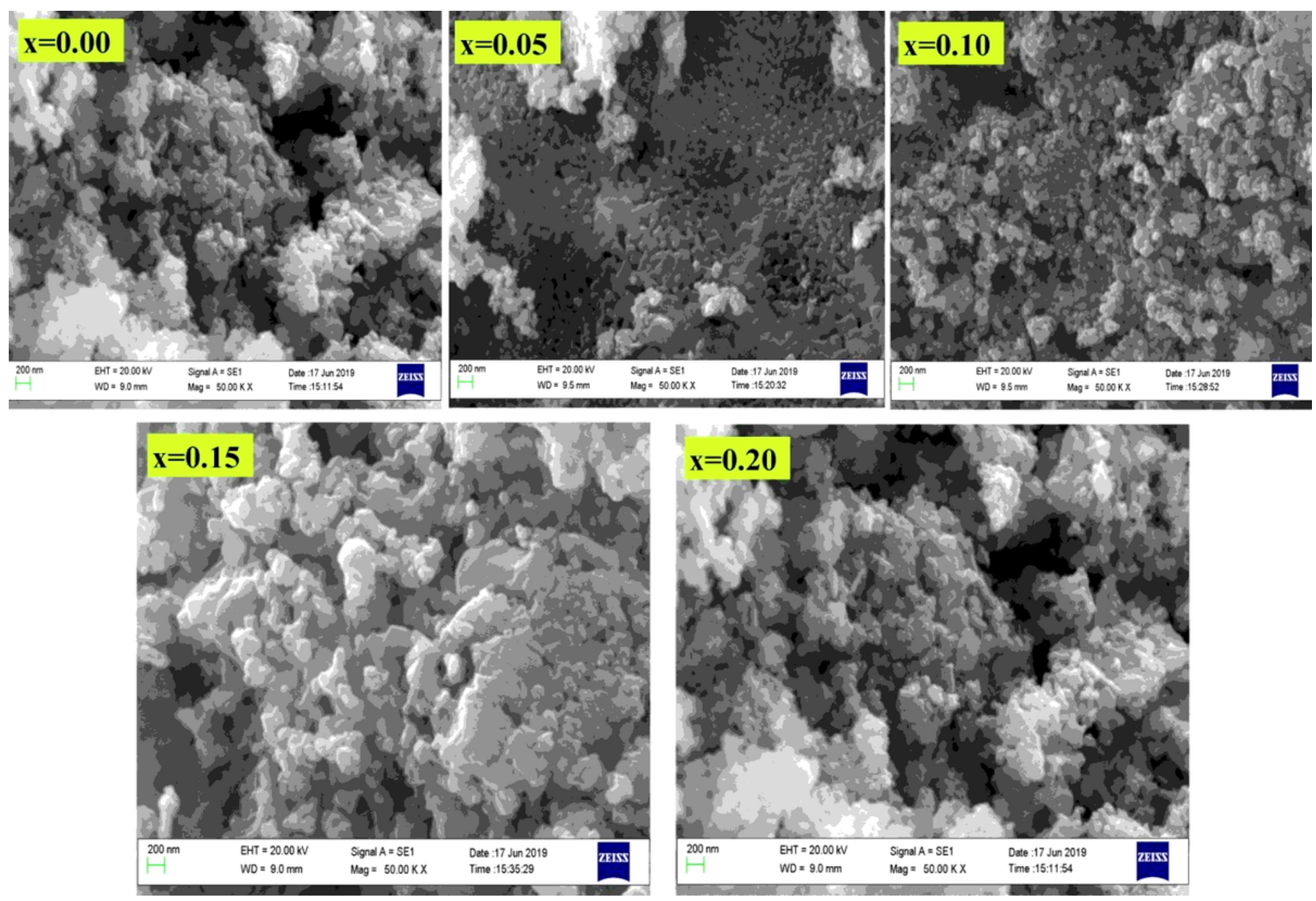

\section{Figure 5}

SEM micrographs of Ni0.6Cd0.4DyxFe2-xO4 nanopowders 

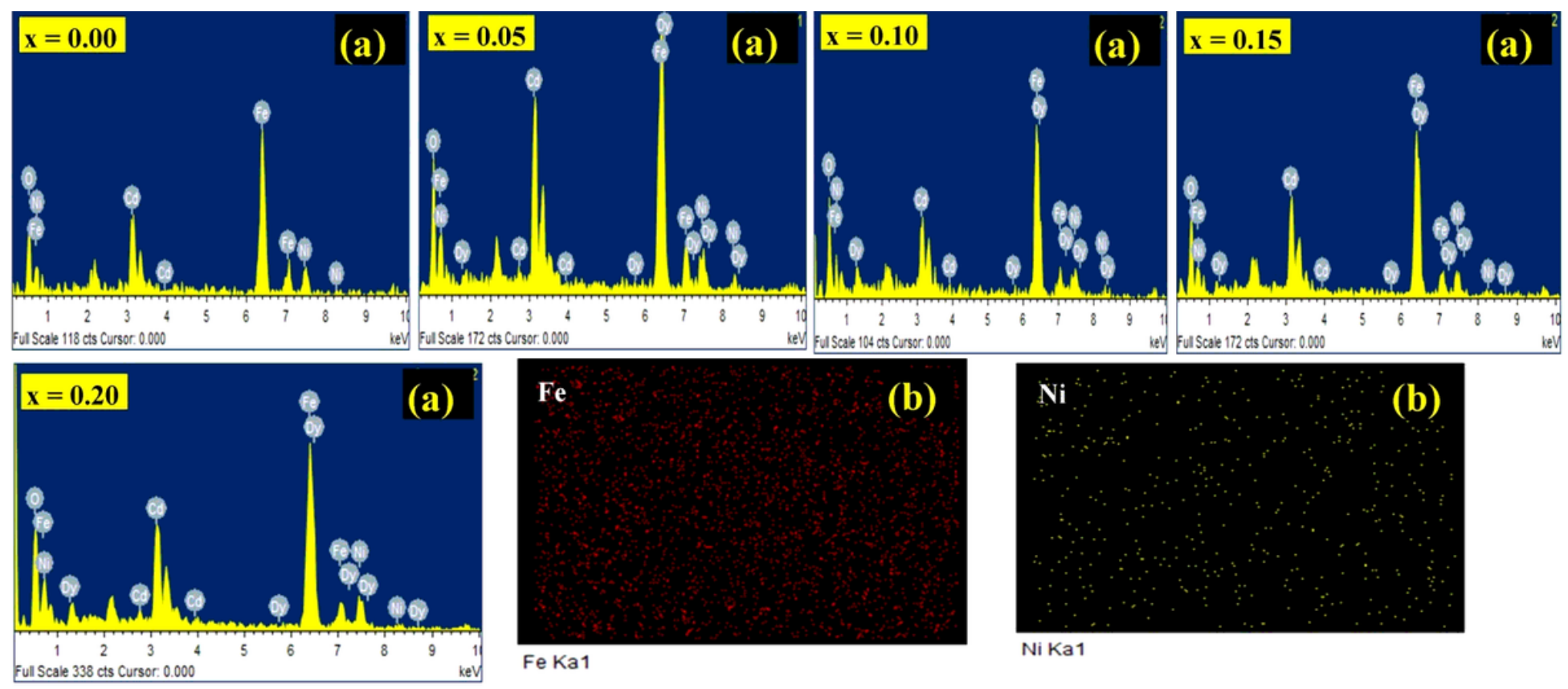

Ni Ka1

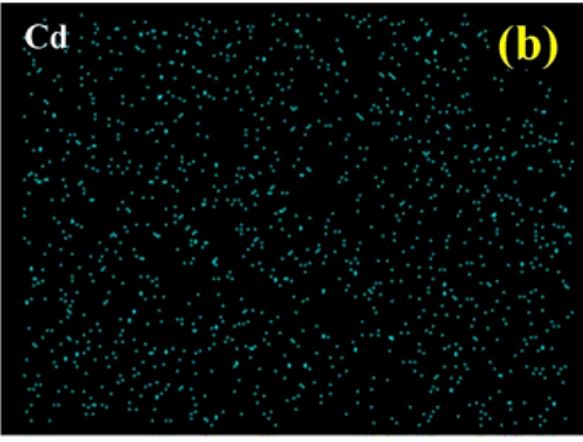

O

(b)

Dy

(b)

Cd La1

O Ka1

Dy La1

Figure 6

(a) EDS spectra and (b) elemental mapping images of Ni0.6Cd0.4DyxFe2-xO4 ferrite Nanoparticles demonstrate the homogeneous distribution of the material, as described in the text.

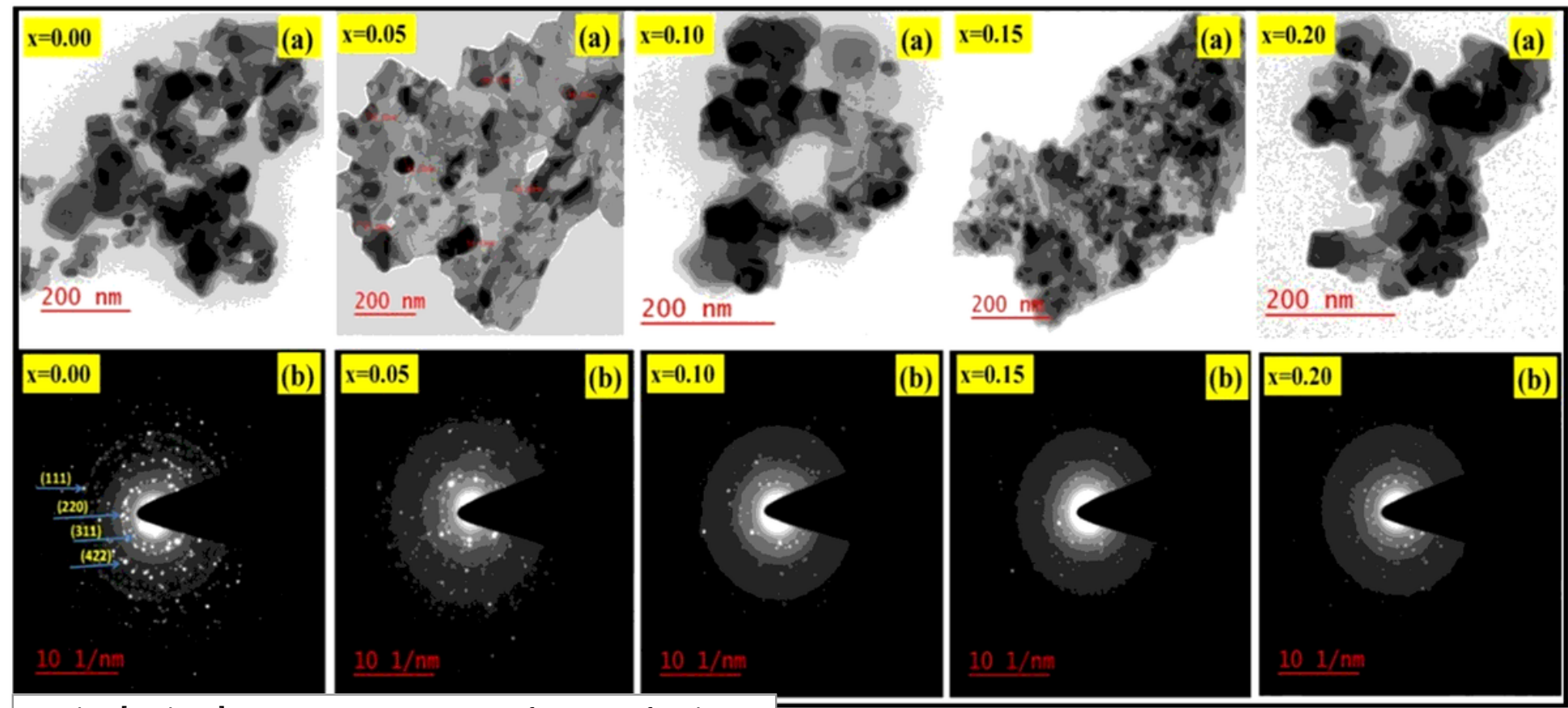


Figure 7

TEM images of Ni0.6Cd0.4DyxFe2-xO4 nanoparticles (a) bright field images and (b) SAED images showing nano polycrystallinity.
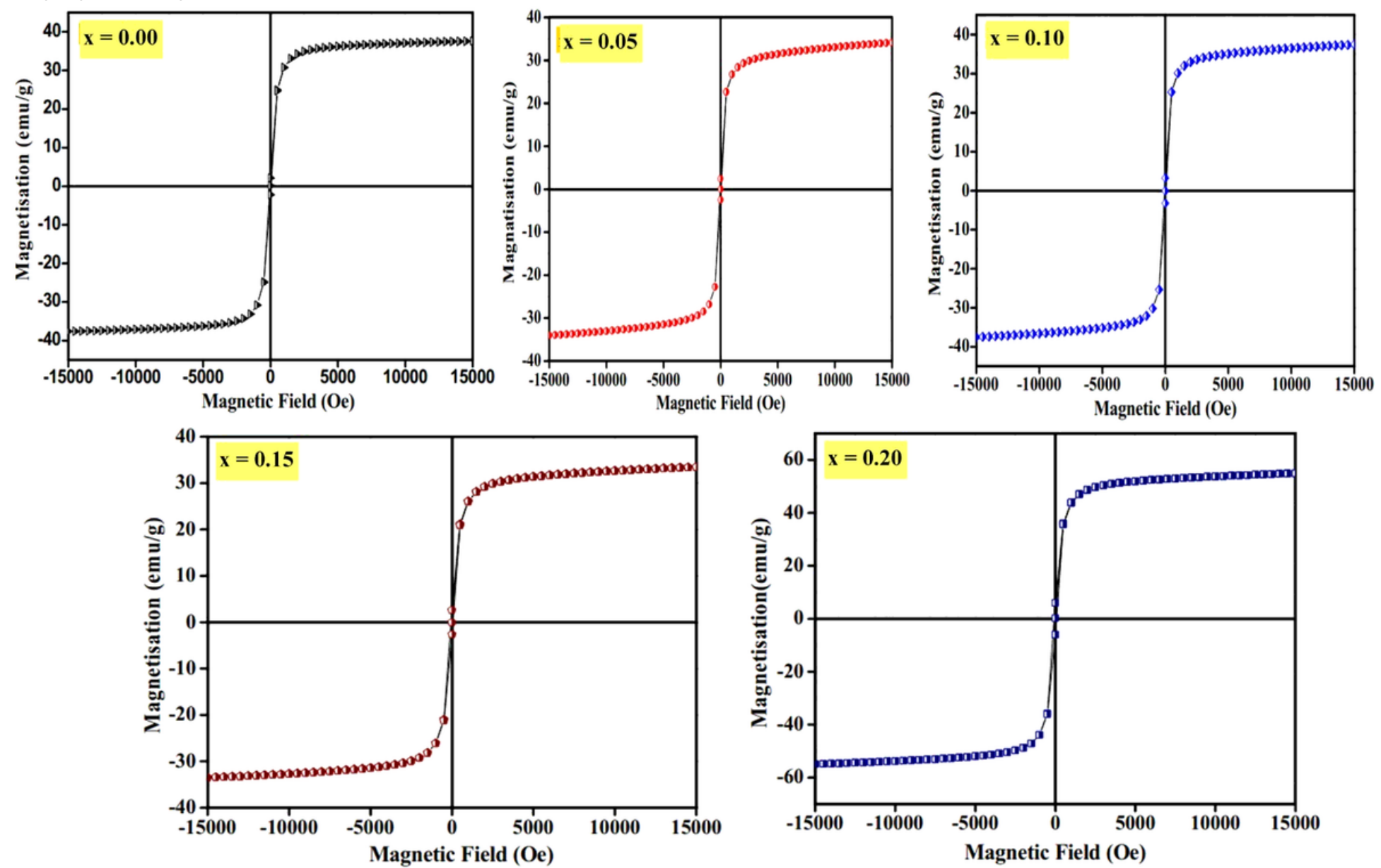

\section{Figure 8}

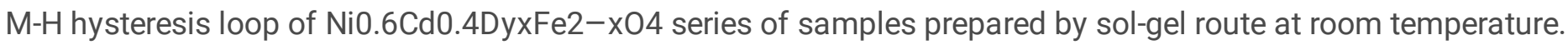



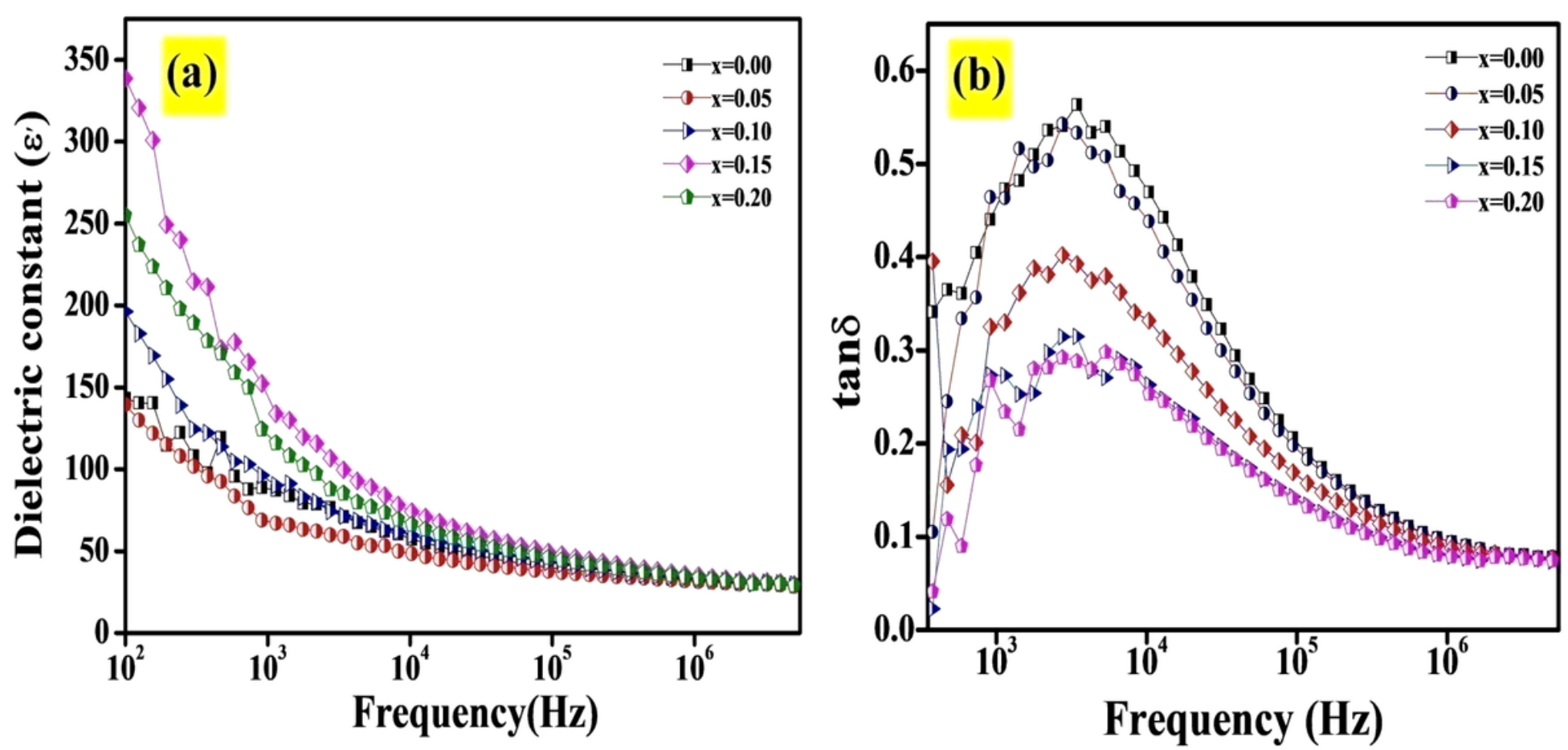

Figure 9

Variation of (a) dielectric constant $\left(\nabla^{\prime}\right)$ and (b) dielectric loss angle (tan $\delta$ ) with frequency for Ni0.6Cd0.4DyxFe2-xO4 series at Room temperature. 